\title{
REVIEWS
}

\section{Synthesis and Physicochemical Properties of Di- and Trivalent Metal-Ammonium Phosphates}

\author{
V. V. Bogdanova and O. I. Kobets \\ Research Institute for Physical Chemical Problems, Belarusian State \\ University, Leningradskaya ul. 14, Minsk, 220030 Belarus \\ e-mail: bogdanova@bsu.by \\ Received November 13, 2014
}

\begin{abstract}
Data on the influence exerted by the synthesis conditions and by the nature and relative amounts of precursor reagents on the properties of metal-ammonium phosphates, promising as components of fire-retardant and fire-extinguishing additives, are summarized and analyzed. The manner in which the solution $\mathrm{pH}$ and nature and relative amounts of the reacting metal-, nitrogen-, and phosphorus-containing compounds affect the phase composition, solubility, aggregative state, and fundamental aspects of thermal transformations of products being synthesized on the basis of di- and trivalent metal-ammonium phosphates in a wide temperature range is determined.
\end{abstract}

DOI: $10.1134 / \mathrm{S} 1070427214100012$

In view of the increasing hazard of occurrence and propagation of anthropogenic, forest, and peat fires, development of ecologically safe and abundant fireretardant agents for synthetic and natural combustible materials is a topical task. The demand is for fire retardants forming no toxic products in thermal decomposition and burning of fire-protected materials. In this regard, the most promising polymer combustion inhibitors are nitrogen- or phosphorus-containing compounds [1], with the most pronounced effect obtained in their joint application. As a rule, deficient organic nitrogen- and phosphorus-containing products are used to impart fireresistant properties to synthetic polymers, and forest combustible materials and peat are fire-protected and extinguished with various mixtures of inorganic salts and organic compounds [2-4].

It was found in [5] that fire-retardant and fireextinguishing properties are inherent in di- and trivalent metal-ammonium phosphates. These compounds are of particular interest because of being comparatively inexpensive and simultaneously containing nitrogen and phosphorus, which is necessary for their application as fire-retardant agents. Burning is extinguished because of the changing conditions of heat-and-mass transfer between the flame zone and a combustible material undergoing thermolysis in the condensed phase. Studies of the mechanism of the fire-resistant action of halogenfree fire-retardant agents have shown that the synergism of N-P-containing combustion-retardants consists in that isolating glassy melts and(or) foamed structures are formed in the pre-flame zone of the condensed phase, with mostly the phosphorus-containing component involved, and the decrease in temperature in the gas zone is due to the interaction of volatile nitrogen compounds with active flame centers [5].

In view of the requirements to efficient fire-fighting formulations for forest combustible materials (FCMs) and peat, a wide group of compounds belonging to the class of double metal-ammonium phosphates can be regarded as a fire-retardant component of fire-extinguishing agents (FEAs) for these natural smoldering materials. In this context, there appeared a need to analyzed published data on how the synthesis conditions affect the aggregative state of the resulting products and their thermal properties at temperatures in the range $200-500^{\circ} \mathrm{C}$, which occur in the condensed phase in combustion of wood and peat.

Because of the wide range of properties determined by the nature and relative amounts of starting reagents and by their synthesis conditions, metal-ammonium phosphates (MAPs) find application in various fields of scientific and business activities. MAPs are used in analytical chemistry for quantitative determination of phosphorus and mag- 
nesium; they have been recommended as the active substance of the film membrane for an electrode exhibiting a selective sensitivity for hydrophosphate ions $[6,7]$. It has been suggested to use the deposition process of poorly soluble MAPs for wastewater purification to remove hydrophosphate and ammonium ions and for reducing the discharge of ammonia to the atmosphere [8-12]. The good ion-exchange properties and the developed specific surface area of MAPs and materials on their basis make it possible to obtain selective ion exchangers, molecular sieves, effective catalysts, and sorbents [13-18]. Owing to their bright coloration, water and light resistance, and luminescent properties, MAPs are used in the industry to obtain insoluble pigments, primer paints, anticorrosion coatings on metals, and phosphors [19, 20]. Some double phosphates of metals serve as a basis for promising functional materials being developed, e.g., for medical purposes (biocompatible implants) or for obtaining heatresistant formulations (fire-resistant coatings, fire-proofed glues and concretes) [21-23]. However, MAPs are the most widely used as phosphorus-containing fertilizers containing, in addition to the two main nutritive elements (nitrogen and phosphorus), microelement metals ( $\mathrm{Mg}, \mathrm{Zn}$, $\mathrm{Cu}, \mathrm{Co}, \mathrm{Mn}$ ). Most of publications devoted to synthesis and study of the physicochemical properties of MAPs are concerned just with this aspect of their application [24-27].

It was suggested in a number of studies carried out in the 1960s [28,29] and later [30-32] that metal-ammonium phosphates [where the metal is aluminum or iron(III), or one of metals in the oxidation state +2 : magnesium, manganese, zinc, copper, cobalt, iron] can be used as additives making cellulose materials (cardboard, paper) and composite wood articles (fiberboards) heat-and-fire resistant. However, the authors of these studies disregarded the influence exerted by the composition and physicochemical properties of MAPs on the fire-protective and fire-extinguishing properties with respect to smoldering natural materials. Powdered MAPs containing one of the above-listed metals were introduced as fire-retardants into composite wood materials with adhesive mixtures. No modern original and review communications devoted to fire-extinguishing and fire-protective properties of MAPs could be found in the literature.

At the same time, MAPs are of interest as fire-retardant agents for cellulose-containing smoldering materials primarily because these compounds contain nitrogen and phosphors, which exhibit a synergistic effect when present together, and their properties can be controlled by changing the composition of the starting components from which they are produced and the synthesis conditions. Therefore, we are going to consider published data on the influence exerted by the nature and relative amounts of starting components and their interaction conditions on the physicochemical and thermal properties of di- or trivalent metal-ammonium phosphates. These properties may be promising for choosing methods that can be used to obtain effective and inexpensive fire-protective MAP-based formulations capable of forming condensed insulating structures and volatile combustion inhibitors at the thermal decomposition temperatures of natural combustible materials.

\section{SYNTHESIS CONDITIONS AND PROPERTIES OF METAL(II)-AMMONIUM PHOSPHATES}

Recent studies concerned with double phosphates with cations of divalent metals $(\mathrm{Mg}, \mathrm{Zn}, \mathrm{Co}, \mathrm{Ni}, \mathrm{Cu}$, $\mathrm{Mn}$, or $\mathrm{Fe}$ ) and ammonium or an alkali metal analyze their structure and such properties promising for modern technology as optical, electrical, and catalytic. It has been shown [33-40] that the conditions in which these products are obtained, solid-phase or prolonged hydrothermal synthesis at high temperatures and pressures, determine their properties.

These methods are hardly suitable for obtaining liquid fire-protective or fire extinguishing formulations for cellulose-containing materials because of requiring gross energy expenditure, special high-pressure autoclaves, or introduction of additional stages of crushing of a substance for its transfer into solution in the finely dispersed state.

According to published data, the most widely used methods for obtaining MAPs from aqueous solutions under normal pressure at room or comparatively low temperature $\left(20\right.$ to $\left.100^{\circ} \mathrm{C}\right)$ in laboratory or industrial conditions are those in which salt solutions of the corresponding metal and ammonium phosphates with varied degree of substitution are mixed [41-47] and metal oxides, hydroxides, or salts are reacted with phosphoric acid, with the subsequent neutralization of the metal phosphate solution under vigorous agitation [48-51]. It should be noted that the exchange interaction of metal salts with soluble phosphates of ammonium or alkali metals is widely used in laboratory practice for obtaining individual metal phosphate salts. 
Another way to obtain MAPs from aqueous solutions, mostly suggested in the patent literature [52-55], consists in that a compound (oxide, hydroxide) of a divalent metal from the group constituted by $\mathrm{Mg}, \mathrm{Mn}, \mathrm{Fe}, \mathrm{Zn}, \mathrm{Cu}, \mathrm{Co}$ is preliminarily mixed under heating with an excess amount of a concentrated alkaline solution [aqueous solution of ammonia, ammonium carbonates and(or) hydroxides, and alkali metal carbonates], and then phosphoric acid is added. This method is used to diminish the content of admixtures of ammonium phosphates (or alkali metal phosphates)) in MAPs. However, MAPs can be contaminated in this case by a metal hydroxide and starting reagents [52]. The resulting powdery crystalline MAPs, subjected to further grinding, have a low dispersity (the average particle size is about $0.5 \mathrm{~mm}$ ) [55]. This method is hardly suitable for synthesizing fireextinguishing formulations in the form of stable aqueous suspensions because its principal disadvantage consists in the need to thoroughly grind the starting reagents for a better occurrence of surface reactions on particles of the metal-containing compound. As a result, it is impossible to obtain a product composed of monodisperse particles. The particle size of the crystalline solid component of the product obtained is coarsened and becomes larger that the initial size of particles of the starting reagent.

A distinctive feature of the synthesis of solid metal phosphates by precipitation from solutions is the long time in which equilibrium is attained in the solution-precipitate system, with metastable intermediate compounds formed in the solution and precipitate. In the process, solid phases represented by MAPs, acid and tertiary metal phosphates, or mixtures of these with MAPs are slowly crystallized [56]. The originally formed amorphous gel- or cream-like precipitate occupying the whole volume of the reaction space undergoes, in the course of time, a change of its chemical and phase composition. Solid individual phosphates of divalent metals and ammonium, which are water-insoluble polycrystalline powders obtained from aqueous dispersions, are commonly synthesized by the standard procedures: prolonged keeping (from several hours to several days or weeks) at heating under a mother liquor layer, filtering, washing with water and ethanol, and drying. Depending on the conditions under which these procedures are performed and their duration, the products being synthesized have different chemical and phase composition and microstructure and, accordingly, different properties.

At the same time, it is not always appropriate to reach equilibrium and obtain a coarsely crystalline precipitate when synthesizing phosphorus-containing products for FEAs. For example, it is undesirable that the originally amorphous should become well crystallized, because it is known that, in contrast to crystalline compounds, those in the amorphous state form more continuous and stronger films on the surface of materials and have better adhesion properties [57]. At the same time, published data indicate that the highest efficiency is observed for fireextinguishing and fire-protective formulations obtained in the form of aqueous colloid solutions or fine dispersions exhibiting a good cooling effect and wetting and film-forming properties [58].

For this reason, of particular interest are publications whose authors obtain MAPs by precipitation from solutions, with formation of colloid solutions, gels, or fine dispersions of individual compounds in the amorphous or finely crystalline state.

According to the available evidence $[35,56]$, the shift of equilibrium toward formation of a compound with a certain phase composition and necessary properties is affected by the molar ratio of the reactants, temperature, concentration, and solution $\mathrm{pH}$. The influences exerted by some of these factors are interrelated and are frequently manifested simultaneously.

The nature of the precipitating agent is of particular importance in syntheses of MAPs by pouring together salt solutions. The role of a precipitating agent is mostly played by tertiary phosphates and hydrophosphates of ammonium (or an alkali metal) in the presence of ammonium dihydrophosphate. In the opinion of the authors of [56], soluble or gel-like comparatively stable complexes of metal salts with $\mathrm{NH}_{4} \mathrm{H}_{2} \mathrm{PO}_{4}$, and precipitates of double metal-ammonium phosphates (from the group of polyvalent materials under consideration) are not formed. In the course of time, soluble complexes disintegrate to give a small amount of a crystalline precipitate of MAP (about $10 \%$ ). If solutions of tertiary phosphates or hydrophosphates of ammonium (or alkali metals) are used as a precipitating agent, precipitates are formed immediately after the solutions are poured together throughout the reaction volume, with the subsequent crystallization of double phosphate hydrates of general formula $\mathrm{M}^{\mathrm{I}} \mathrm{M}^{\mathrm{II}} \mathrm{PO}_{4} \cdot n \mathrm{H}_{2} \mathrm{O}$ $\left(\mathrm{M}^{\mathrm{I}}\right.$ is the cation of ammonium or an alkali metal) $[37,56]$. This requires $1.5-2$ times more concentrated solutions of an alkali metal phosphate, compared with the corresponding solutions of ammonium phosphates.

Important conditions for obtaining MAP as a result of an exchange reaction between a soluble salt (chloride, 
sulfate, or nitrate) and ammonium phosphates with various degrees of substitution is the solution concentration and reagent ratio. Double metal-ammonium phosphates of all the divalent metal under consideration are, as a rule, obtained as a crystalline double salt of composition $\left[\mathrm{NH}_{4} \mathrm{MPO}_{4} \cdot n \mathrm{H}_{2} \mathrm{O}\right]$ from both dilute and concentrated solutions on keeping the precipitate under mother liquor. It is believed tat the optimal ratio in this case is a threeto sixfold excess of the precipitating agent, ammonium hydrophosphate, over a metal salt solution, compared with the stoichiometric optimal concentrations: $0.5-1.0 \mathrm{M}$ solution of a divalent metal salt and 1.0-3.0 M solution of $\left(\mathrm{NH}_{4}\right)_{2} \mathrm{HPO}_{4}[37,48]$. It has been found [56] that, at the equimolar ratio between ammonium hydrophosphate and the salt of a divalent metal (manganese, copper, zinc, cobalt), the precipitate contains, together with MAPs, a mixture of acid and tertiary phosphates, and, if the metal salt is present in excess over ammonium phosphate, a tertiary metal phosphate is formed. In concentrated solutions, a stronger influence on the composition and particle size of phases being precipitated is exerted by the rate of pouring together and agitation of reagents: a low rate of pouring together of solutions and higher agitation intensity favor synthesis of compounds with a higher degree of dispersity.

Depending on the temperature of solution salts being mixed, precipitates of compounds containing various amounts of hydration water are obtained. It has been noted $[48,50]$ that the rate at which the crystalline structure of MAPs is formed grows with increasing temperature. When solutions heated to a temperature lower than $50^{\circ} \mathrm{C}$ are poured together and the bulky gel-like precipitate is kept under a mother liquor layer at this temperature, metal-ammonium phosphate hexahydrates of such metals as cobalt, nickel, and magnesium commonly crystallize [50]. At higher temperatures $\left(55-100^{\circ} \mathrm{C}\right)$, phosphate monohydrates of cobalt, nickel, magnesium, copper, iron(II) and ammonium are formed [37, 50]. Zincammonium phosphate, which is commonly precipitated in the anhydrous form, and manganese-ammonium phosphate monohydrate have been obtained at room temperature $[46,59]$.

The presence of hydration water in fire-retardant additives forming a coating or a film on the surface of FCMs upon evaporation of moisture is an additional positive property required for fire protection of cellulosecontaining materials. Also important are the temperature ranges of decomposition of crystal hydrates. It is known that, under the forest fire conditions in thermolysis of FCMs treated with a fire-protective formulation, compounds containing hydration water can decompose with release of water. This lowers the temperature on the surface of the material undergoing pyrolysis $[58,60]$.

It has been found experimentally $[42,61]$ that there are significant differences in thermal behavior between anhydrous and hydrated phosphates of divalent metals ( $\mathrm{Mg}, \mathrm{Zn}, \mathrm{Cu}, \mathrm{Co}, \mathrm{Ni}, \mathrm{Mn}$ ) and ammonium: depending on the amount of hydration water, they undergo transformations in different temperature ranges. The thermal decomposition of anhydrous MAPs of the above divalent metals begins at temperatures higher than $350^{\circ} \mathrm{C}$, and that of monohydrates, beginning at $130-260^{\circ} \mathrm{C}$ [43]. The thermolysis occurs with stage-by-stage release of water separately from, or together with ammonia and is accompanied by polycondensation of phosphate ions. It should be noted that the release of water and ammonia into the gas phase occurs in thermal decomposition of MAPs during the entire thermolysis process, occasionally up to temperatures of about $400-450^{\circ} \mathrm{C}[41,47]$. It is also important to take this factor into account when considering the possibility of using MAPs as fireretardant agents. For example, thermolysis of phosphate hexahydrates of divalent metals and ammonium, which are unstable in air even at room temperature in the case of compounds of magnesium and cobalt, begins with release of a substantial amount of hydration water at rather low temperatures (below $100^{\circ} \mathrm{C}$ ) [61]. MAPs of this kind are unstable under standard conditions or undergo lowtemperature decomposition, i.e., they are hardly suitable as fire-retardant agents before the onset of thermolysis of wood and peat.

Phosphates of divalent metals and ammonium are commonly obtained by mixing of salt solutions under heating, with the result that there occurs rather rapid crystallization with coarsening of particles of the synthesis product, which originally precipitates from the ammonium phosphate solution as a gel-like bulky substance. One more disadvantage of this synthesis method is that a phosphate with mixed anions is formed [56], which affects not only the composition of metal phosphates, but also their dispersity, crystallization rate, and solubility.

Another widely used method for obtaining MAPs from solutions is the double-stage synthesis: heating of various metal-containing raw materials mixed with phosphoric acid, followed by treatment with gaseous ammonia or 
with a mixture of an ammonia solution with an alkali. This method yields, depending on synthesis conditions, MAPs, acid metal phosphates, or mixtures of these with MAPs in the form of powdered crystalline compounds [49-51]. In this case, the originally gel-like poorly crystallized precipitate is kept at $90-100^{\circ} \mathrm{C}$ during a certain time. The reactions yielding metal phosphates and MAPs occur simultaneously to give in solution ammonium hydro- and dihydrophosphate [24].

An important condition for synthesis of MAPs by the second method is the phosphoric acid concentration, which is determined experimentally for each particular case when obtaining a metal phosphate solution. It has been found $[56,62]$ that the phosphoric acid concentration at which the rate-determining stage of the process, dissolution of metal-containing raw materials, is the fastest is in the range $30-75 \%$, and the temperature of the reaction mixture is $20-120^{\circ} \mathrm{C}$, depending on the nature of a cation and the physical state of the compound being dissolved. At acid concentrations exceeding $75 \%$, the viscosity of the system sharply grows and the product contains unreacted substances because of the hindered mass transfer [56].

Of particular importance in the neutralization of an acid metal phosphate solution with an ammonia solution is the acidity of the resulting aqueous phosphate suspension because phosphates of various phase compositions or a mixture of these is precipitated at different $\mathrm{pH}$ values. For example, in ammoniation of a metal phosphate solution (binder) containing copper(II) ions, the main phase of the crystalline precipitate has a composition $\mathrm{NH}_{4} \mathrm{CuPO}_{4} \cdot \mathrm{H}_{2} \mathrm{O}$ at $\mathrm{pH}$ 6.8-7.0; cobaltammonium phosphate monohydrate is obtained from a solution containing cobalt(II) at $\mathrm{pH}$ 4.6-5.9. If the $\mathrm{pH}$ value is lowered to $2.5-6.0$ in the first case and to $3.9-4.2$ in the second, a mixture of a metal-ammonium phosphate with hydrophosphate of the metal is formed $[49,51]$. In neutralization of a magnesium-containing phosphate solution with gaseous ammonia to $\mathrm{pH}$ 5.0-5.6, crystalline $\mathrm{NH}_{4} \mathrm{MgPO}_{4} \cdot \mathrm{H}_{2} \mathrm{O}$ precipitates, and an acid salt, magnesium hydrophosphate, as obtained at $\mathrm{pH} 4.4$ [14]. Zinc-ammonium phosphate is precipitated with ammonia from a zinc-containing phosphate solution at $\mathrm{pH}$ values in the range 3.0-6.3, whereas no precipitate is formed at lower $\mathrm{pH}$ [51].

There are no recommendations on obtaining MAPs in the form of stable dispersions with properties required for FEM. The synthesis conditions of individual MAPs are oriented toward a fast crystallization of originally poorly crystallized bulky precipitates from aqueous solutions in order to obtain crystalline powders. There are no data, either, on application of individual metal(II)ammonium phosphates as fire-retardant agents for fire-extinguishing aqueous dispersions. There is only evidence about introduction of these phosphates in the solid crystalline form with glue formulations into the bulk of wood materials [29]. Consequently, when obtaining MAPs by a particular variant of synthesis in solution to use these compounds as components of liquid FEM, it is necessary to find experimentally the optimal synthesis conditions: concentrations of solutions of the reacting salts or phosphoric acid, $\mathrm{pH}$ of the medium, nature of a divalent metal compound, agitation rate, and reaction mass temperature. Simultaneously, it is necessary to create conditions for obtaining FEM as stable gels or dispersions in which MAPs are in the amorphous or finely crystalline state suitable for application to FCMs or peat with spraying devices.

At the same time, it is known [62] that, in contrast to ions of divalent metals, cations of trivalent metals (aluminum, iron) can form in phosphate solutions numerous stable complexes with orthophosphate ions, which can be used to obtain, under certain synthesis conditions, finely dispersed amorphous and gel-like precipitates of insoluble phosphates. In addition, there is evidence that powder-like phosphates of trivalent metals (aluminum or iron) and ammonium as additives to fireprotecting glue formulations for wood materials are more effective than MAPs based on divalent metals [29]. For this reason, it is important to give particular attention to the synthesis conditions of aluminum- and iron(III)ammonium phosphates and to their physicochemical and thermal properties determining the possibility of their application as promising fire-retardant additives to fireextinguishing liquid formulations for FCMs and peat.

\section{VARIATION OF THE COMPOSITION AND PHYSICOCHEMICAL PROPERTIES OF ALUMINUM- AND IRON(III)- AMMONIUM PHOSPHATES WITH SYNTHESIS CONDITIONS}

The ability to form double phosphates with cations of ammonium or alkali metals is characteristic of not only aluminum and iron(III), but also a number of transition metals. Among metals with oxidation state +3 , compounds of this kind are also formed by gallium, indium, vanadium, 
chromium, bismuth, scandium, and rare-earth elements $[13,63-65]$, and among those with oxidation states +4 and +5 , by zirconium, titanium, and vanadium $[66,67]$. Despite the large number of studies concerned with double phosphates of ammonium and polyvalent metals, data on the synthesis conditions and properties of these compounds are scarce and not systematized. Published data on syntheses of fire-protecting or fire-extinguishing aqueous compositions based on phosphates of trivalent metals and ammonium are lacking. There are only single reports [31] mentioning application of complex mixtures of crystalline powders containing products produced by heating of aluminum- or iron(III)-ammonium phosphates as fire-protective additives introduced in the stage of fabrication of fiberboards.

The wide diversity of double phosphates of complex composition is due to the different synthesis conditions, nature, and ratio between the radii of the mono- and trivalent cations [68]. Complex double phosphates may contain, in addition to cations of mono- and trivalent metals or ammonium and $\mathrm{H}_{n} \mathrm{PO}_{4}^{(3-n)-}$ anions, also hydroxy groups and water molecules. The most widely occurring compounds of double orthophosphates mono- and trivalent metals are divided, as regards their composition, into three groups [68-70]: (1) tertiary orthophosphates of composition $\mathrm{M}_{3}^{\mathrm{I}} \mathrm{M} I \mathrm{II}\left(\mathrm{PO}_{4}\right)_{2}, \mathrm{M}_{3}^{\mathrm{I}} \mathrm{M}_{2}^{\mathrm{III}}\left(\mathrm{PO}_{4}\right)_{3}$; (2) acid orthophosphates of the type $\mathrm{M}^{\mathrm{I}} \mathrm{M}^{\mathrm{III}}\left(\mathrm{HPO}_{4}\right)_{2} \cdot n \mathrm{H}_{2} \mathrm{O}$, $\mathrm{M}_{x}^{\mathrm{I}} \mathrm{M}_{y}^{\mathrm{IIII}}\left(\mathrm{HPO}_{4}\right)_{z}\left(\mathrm{PO}_{4}\right)_{c} \cdot n \mathrm{H}_{2} \mathrm{O}, \mathrm{M}_{x}^{\mathrm{I}} \mathrm{M}_{y}^{\mathrm{III}}\left(\mathrm{H}_{2} \mathrm{PO}_{4}\right)_{z}\left(\mathrm{HPO}_{4}\right)_{c} \cdot n \mathrm{H}_{2} \mathrm{O}$, $\mathrm{M}_{2}^{\mathrm{I}} \mathrm{M}^{\mathrm{III}}\left(\mathrm{H}_{2} \mathrm{PO}_{4}\right)\left(\mathrm{HPO}_{4}\right)_{2}\left(\mathrm{H}_{3} \mathrm{PO}_{4}\right) \cdot n \mathrm{H}_{2} \mathrm{O}$, where $\mathrm{M}^{\mathrm{I}}=$ $\mathrm{NH}_{4}, \mathrm{Na}, \mathrm{K}, \mathrm{Rb}, \mathrm{Cs}, \mathrm{H}_{3} \mathrm{O} ; \mathrm{M}^{\mathrm{III}}=\mathrm{Al}, \mathrm{Fe}, \mathrm{Ga}, \mathrm{In}, \mathrm{V}$; and (3) basic orthophosphates $\mathrm{M}^{\mathrm{I}} \mathrm{M}^{\mathrm{III}} \mathrm{OH}\left(\mathrm{PO}_{4}\right)_{2} \cdot n \mathrm{H}_{2} \mathrm{O}$, $\mathrm{M}^{\mathrm{I}} \mathrm{M}^{\mathrm{III}}(\mathrm{OH}) \mathrm{PO}_{4} \cdot n \mathrm{H}_{2} \mathrm{O}, \mathrm{M}_{3}^{\mathrm{I}} \mathrm{M}^{\mathrm{III}}(\mathrm{OH})\left(\mathrm{HPO}_{4}\right)\left(\mathrm{PO}_{4}\right), \mathrm{M}^{\mathrm{III}}=$ $\mathrm{Al}, \mathrm{Fe}, \mathrm{Ga}$.

It follows from published data $[68,71,72]$ that two methods are the most widely used for obtaining crystalline powders of the above phosphorus-containing compounds of trivalent metals: solid-phase synthesis from melts, frequently used to obtain anhydrous tertiary double orthophosphates and synthesis from solutions. MAPs are synthesized from aqueous solutions by the hydrothermal method at elevated temperatures and(or) pressures [64, 68, 70-74]. This mostly yields tertiary double metal-ammonium phosphates. Double basic salts are characteristically formed in the case of small cations (aluminum, iron, gallium), which are commonly exist in aqueous solutions in the form of hydroxo complexes [68].

In recent years, the sol-gel method has gained wide application for synthesis of double metal-ammonium phosphates [75]. It is used to obtain not only metal phosphates, but also compounds of mixed skeleton structure of the type $\left\{\mathrm{M}_{2}\left(\mathrm{XO}_{4}\right)^{n-}\right\}_{3 \infty 0}(\mathrm{M}$ is a metal in the oxidation state from +1 to $+5, \mathrm{X}=\mathrm{P}, \mathrm{Si}, \mathrm{As}, \mathrm{S}, \mathrm{Mo}, \mathrm{W}$ ) [76]. The sol-gel method for synthesis of homogeneous finely dispersed powders from solutions includes the subsequent prolonged thermal treatment of the resulting products to form a prescribed crystalline structure. There is no published information about obtaining MAPs in the form of stable aqueous dispersions by the sol-gel method.

Depending on the intended purpose of MAPs, a particular synthesis method is used. In view of the specific requirements to forest fire control, it is the most appropriate to obtain fire-protective and fire-extinguishing formulations for FCMs and peat on the aqueous basis in the form of fine dispersions or gels. The synthesis of MAPs from aqueous solutions is the most economical and simple as compared with thermal or hydrothermal synthesis techniques.

Compounds of aluminum and iron(III) are the most completely studied among trivalent metal-ammonium phosphates produced from solutions. In syntheses of divalent metal-ammonium phosphates, the solutionprecipitate equilibrium is comparatively easily attained and crystalline products of a certain composition corresponding to the formula $\mathrm{NH}_{4} \mathrm{M}^{\mathrm{II}} \mathrm{PO}_{4} \cdot \mathrm{H}_{2} \mathrm{O}$ are formed. By contrast, it is difficult to prognosticate the composition of trivalent metal-ammonium phosphates and, in particular, those of aluminum and iron(III). In this case, a mixture of amorphous and crystalline phases is frequently formed, with their composition determined by the synthesis conditions and by the relative amounts and nature of the starting reagents [68]. Analysis of published data demonstrates the absence of any recommendations on synthesis of trivalent metal-ammonium phosphates of prescribed composition or procedures for their synthesis as stable fine aqueous dispersions or gels. This is accounted for by the multitude of interrelated factors affecting the structure and, accordingly, the properties of the final products.

To make a substantiated choice of the synthesis conditions of MAPs to be used as combustion retardants, it is primarily necessary to clearly formulate requirements to the supposed properties of ammonium phosphates of aluminum and iron. For example, with consideration for the published data on the mechanism of the fire-protective and fire-extinguishing action of combustion inhibitors, 
the products being synthesized should have the following preferable properties: high dispersity and good adhesion to the surface being protected and occurrence of thermal transformations in a certain temperature range to give insulating glassy or foamed melts and volatiles that affect the physicochemical processes in the flame.

The table lists published data on the chemical and phase composition of crystalline aluminum and iron phosphates precipitated from solutions in relation to the nature of a metal, relative amounts of reagents, nature of the precipitating agent, $\mathrm{pH}$ of the medium, and temperature. MAPs were obtained by precipitation with ammonium hydroxide and(or) urea, hydroxides of alkali metals [24, 77-85], and pouring together of a soluble aluminum salt and ammonium phosphates with various degrees of substitution [86]. The synthesis was performed under vigorous agitation, with the originally amorphous or poorly crystallized gel-like bulky precipitates kept for a long time (from several days to several weeks) under a mother liquor layer to form powders of crystalline compounds. The powdery crystalline and amorphous synthesis products were mixtures of various compounds. Their composition was identified by chemical and X-ray phase analyses and IR spectroscopy $[79-82,86]$. Obtaining MAPs in the form of stable aqueous dispersion was not among the goals of these studies.

Let us analyze the effect of the solution $\mathrm{pH}$, temperature, reagent ratio, and nature of a metal and precipitating agent on the physicochemical properties of MAPs.

The solution acidity affects the chemical and phase composition of MAPs and, accordingly, their solubility. For example, it has been found [80] that all aluminumammonium of various compositions, produced via interaction of ammonia and aluminum compounds in a phosphoric acid solution in a wide $\mathrm{pH}$ range (1.2-9.0), are poorly soluble in water. The least soluble isthe compound $\mathrm{NH}_{4} \mathrm{AlH}_{2}\left(\mathrm{PO}_{4}\right)_{2} \cdot 0.5 \mathrm{H}_{2} \mathrm{O}$ precipitated in a weakly acidic or neutral medium ( $\mathrm{pH} \sim 5.5)$. With the acidity of solutions both increasing and decreasing relative to this $\mathrm{pH}$ value, the solubility of MAPs somewhat increases due to the amphoteric nature of aluminum.

In neutralization of phosphoric acid solutions containing aluminum or iron(III) ions, salts or various chemical compositions or mixtures of these are obtained, depending on the solution $\mathrm{pH}$ and nature of the neutralizing agent [79-82]. Hydrated acid aluminumammonium and iron-ammonium phosphates are, as a rule, precipitated in the $\mathrm{pH}$ range 3.0-5.6, and hydrated tertiary phosphate together with acid phosphates, at pH 6 .

At $\mathrm{pH}$ 6-9, tertiary and basic anhydrous or hydrated MAPs are formed.

A study of the influence exerted by the acidity of the medium on the phase composition of MAPs has shown that, in the $\mathrm{pH}$ range 3-6, double aluminum-ammonium phosphates are mixtures of amorphous and finely crystalline poorly filterable precipitates, whereas at $\mathrm{pH}$ 4.5-5.5, the MAP precipitates are fully amorphous [81].

The effect of the nature of the trivalent metal on the phase composition of MAPs consists in that iron compounds are precipitated in a wider range of reagent concentrations and solution $\mathrm{pH}$ values than the corresponding compounds of aluminum [79, 80].

The temperature factor in the synthesis of MAPs mostly affects the degree of hydration of the compounds obtained. For example, MAPs synthesized at room temperature contain, depending on $\mathrm{pH}$ and concentration of reagents (acid and ammonia solution), 12 to 24 molecules of water per formula unit of the salt $[81,82,85]$. In the case of precipitation of aluminum-ammonium phosphates at a higher temperature $\left(80^{\circ} \mathrm{C}\right)$, less hydrated products are formed, and anhydrous aluminum-ammonium phosphate is obtained if the temperature is raised to $100^{\circ} \mathrm{C}[79,80]$. The degree of MAP hydration reflects upon the thermal properties of the compounds. According to the available published data [68], anhydrous tertiary double phosphates of trivalent metals (including aluminum and iron) are thermally stable. When metal phosphates of composition $\mathrm{M}_{3}{ }^{\mathrm{I}} \mathrm{Me}{ }^{\mathrm{III}}\left(\mathrm{PO}_{4}\right)_{2}\left(\mathrm{M}^{\mathrm{I}}\right.$ is an alkali metal $)$ are heated to $900^{\circ} \mathrm{C}$ only crystalline modifications undergo transitions [61, 68]. Complex acid and basic MAPs that include $\mathrm{HPO}_{4}{ }^{2-}$, $\mathrm{H}_{2} \mathrm{PO}_{4}^{-}$, or $\mathrm{OH}^{-}$anions and water molecules differently bound in the structural units of these compounds have lower decomposition onset temperatures. In these cases, the thermolysis of MAPs occurs in a wider temperature range $[61,74,86]$, beginning at $100-180^{\circ} \mathrm{C}$ and up to $410-530^{\circ} \mathrm{C}$, with simultaneous or successive release of water, ammonium, and formation of condensed phosphates.

Based on these data, we can conclude that including into MAPs hydroxy groups formed in hydrolysis of trivalent metal salts in dilute or alkaline solutions, and also hydrophosphate ions and water molecules, leads to a decrease in the decomposition onset temperature of a salt to values lower than the decomposition onset temperature of wood $\left(220^{\circ} \mathrm{C}\right)$. 


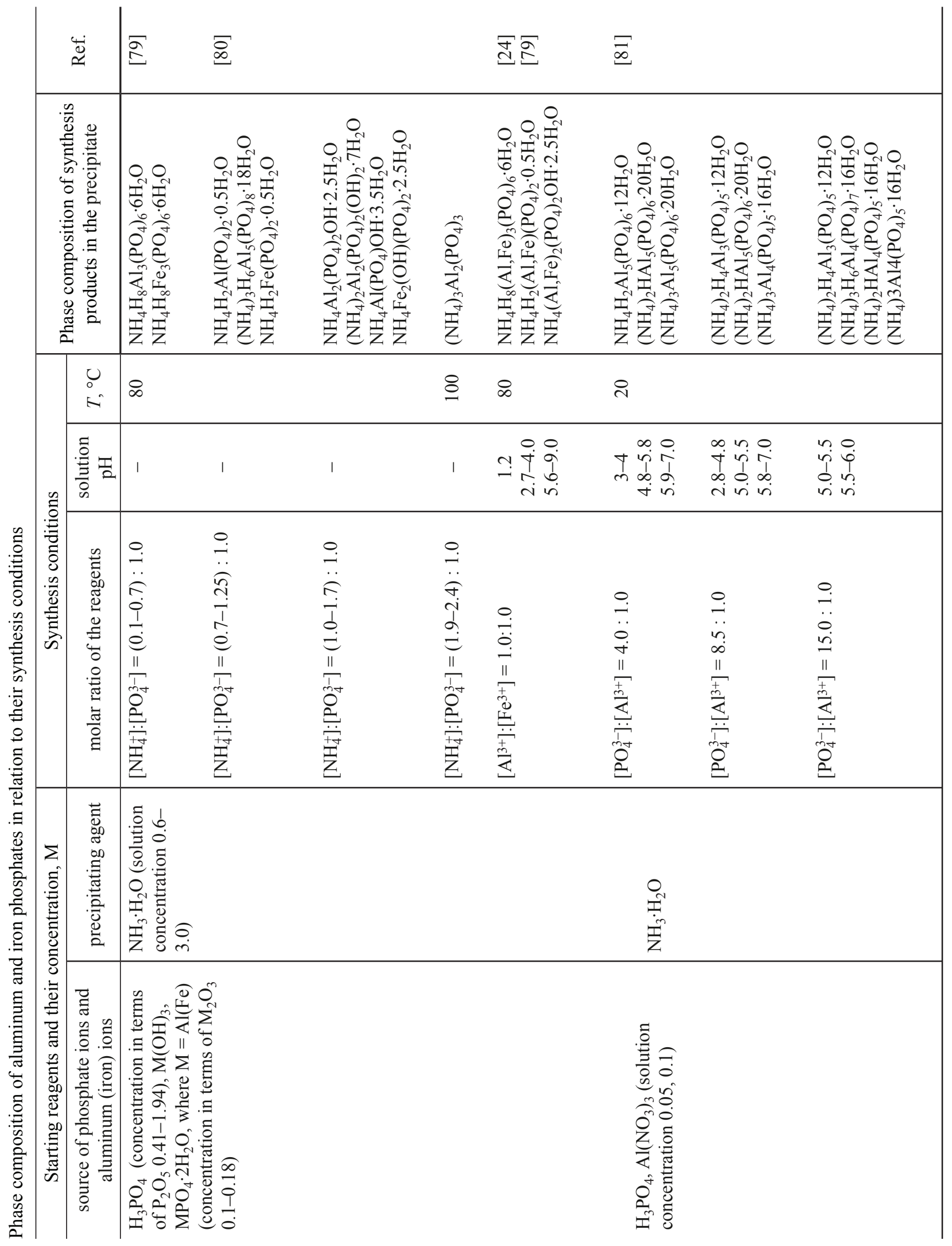




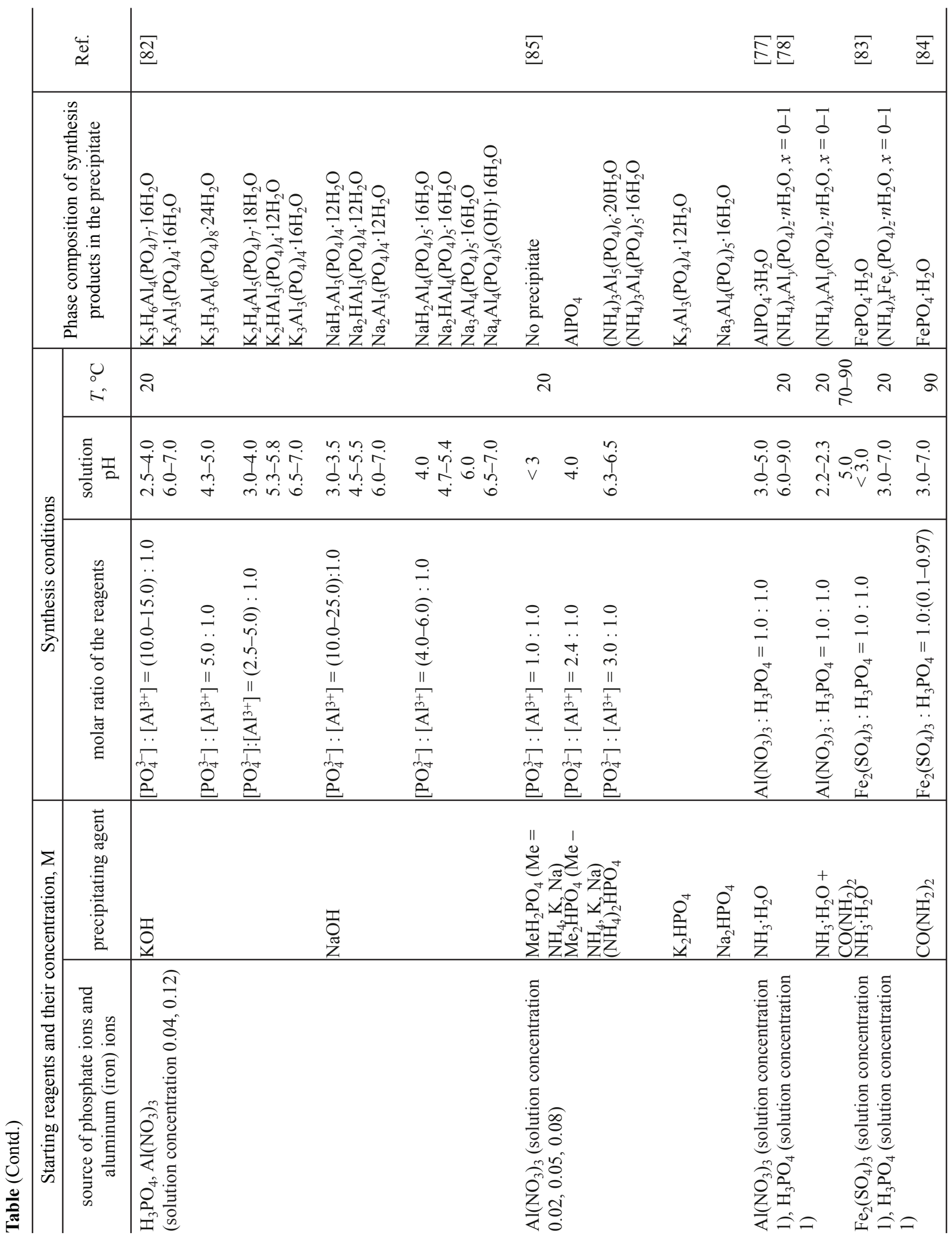


The dependence of the composition, structure, and properties of MAPs $n$ synthesis conditions (concentration of reagents, acidity of the solution and its temperature) is to be taken into account when obtaining MAPs as components of fire-extinguishing formulations.

The nature of the precipitating agent and the reagent ratio are important conditions for obtaining MAPs with prescribed composition and properties. When MAPs are produced by mixing of ammonium (or alkali metal) phosphate solution with a soluble aluminum salts, the composition of the resulting compound depends on the nature of the monovalent cation and phosphate anion. The dependence of the composition of the compounds obtained on the chosen precipitating agent was studied in [85]. For example, upon addition of $\mathrm{MH}_{2} \mathrm{PO}_{4}(\mathrm{M}=$ $\mathrm{NH}_{4}^{+}, \mathrm{Na}^{+}, \mathrm{K}^{+}$to an aluminum salt solution, MAPs are precipitated incompletely because of the formation of stable soluble complexes and gelation. Hydrophosphates of ammonium or alkali metals cause precipitation of MAPs at a no less than fourfold excess of phosphate ions over aluminum ions. X-ray-amorphous MAPs were obtained under these conditions, at a smaller excess of phosphate ions, only tertiary aluminum phosphate was found in the precipitate. Depending on the nature of the precipitating cation, different molar ratios of the starting reagents, soluble salt of $\mathrm{M}^{\mathrm{III}}$ and $\mathrm{M}^{\mathrm{I}}$ phosphate $\left(\mathrm{M}^{\mathrm{I}}=\right.$ $\mathrm{NH}_{4}^{+}, \mathrm{Na}^{+}, \mathrm{K}^{+}$, are required. For example, a substantially larger amount of such a precipitating agent as sodium hydrophosphate is required for obtaining aluminumammonium phosphate, compared with the same salt of potassium or ammonium.

When MAPs double phosphates of an alkali metal and a trivalent metal are produced by neutralization of metal phosphate solutions with an ammonia solution or potassium or sodium hydroxide, a substantially larger excess of alkali metal hydroxides is also required, compared with the ammonia solution [81, 82].

The nature of the monovalent precipitating cation $\mathrm{M}^{\mathrm{I}}$ $\left(\mathrm{M}^{\mathrm{I}}=\mathrm{NH}_{4}, \mathrm{Na}, \mathrm{K}\right)$ affects the onset temperature of the thermal decomposition of MAPs and the final products of its thermolysis [61].

In syntheses of effective aqueous fire-protective and fire-extinguishing agents (FPAs and FEAs), it is important to obtain their components in a finely dispersed crystalline or amorphous state. A high dispersity of the poorly soluble components of FPAs and FEAs is necessary for obtaining formulations with service and physicochemical properties required for fire protection and fire extinguishing: temporal stability of a dispersion, its good adhesion to wood, and the atmosphere resistance of the coating obtained on a material being protected.

No evidence could be found in the literature about

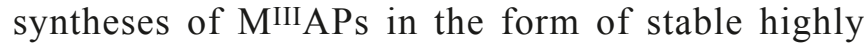
dispersed suspensions used as FPAs. There have been only several reports describing the precipitation conditions of amorphous aluminum-ammonium or iron-ammonium phosphates of nonstoichiometric composition for their recovery from aqueous dispersions or gels in the form of amorphous powders possessing catalytic or sorption properties $[77,78,83,84]$. These studies were concerned with the precipitation of aluminum or iron(III) salts dissolved in phosphoric acid with solutions of ammonia and(or) urea. It is possible to clearly trace by the example of these studies how the nature of a precipitating agent and a trivalent metal compound, the reagent ratio, and $\mathrm{pH}$ value affect the phase composition of the amorphous compounds being obtained. If ammonia solutions are used as a source of ammonium ions and $\mathrm{pH}$-adjusting agent $[77,78]$, bulky amorphous precipitates are formed at the molar ratio $\mathrm{Al}\left(\mathrm{NO}_{3}\right)_{3}: \mathrm{H}_{3} \mathrm{PO}_{4}=1: 1$ and pH 6-9. In these conditions, aluminum-ammonium precipitates have a nonstoichiometric composition of general formula $\left(\mathrm{NH}_{4}\right)_{x} \mathrm{Al}_{y}\left(\mathrm{PO}_{4}\right)_{z} \cdot \mathrm{H}_{2} \mathrm{O}$, where $x=0-1$. The influence exerted by the trivalent metal ion is manifested in that amorphous iron compounds similar to nonstoichiometric ammonium-containing aluminophosphates are precipitated in at $\mathrm{pH} \geq 3-7$ $[83,84]$. At the same reagent ratio in a more acid medium $(\mathrm{pH}<3)$, only amorphous tertiary iron(III) phosphate is precipitated, and at $\mathrm{pH} 3-5$, the corresponding aluminum compound $[77,83]$. It has been found that the dispersity of aluminum- or iron-ammonium phosphates precipitated with ammonia is affected by the rate at which ammonium ions are introduced during the synthesis: if this rate is raised, coarsely dispersed precipitates are formed instead of those similar to a gel. If MAPs are synthesized with only urea used as a precipitating agent, which can serve as a source of ammonia as a result of hydrolysis under heating $\left(70-90^{\circ} \mathrm{C}\right)$, gel-like products with high dispersity over the whole reaction volume are obtained. It should be noted that obtaining a substance in a gel-like amorphous state is of particular interest because just this states provides properties necessary for FPAs.

When choosing a precipitating agent, it is necessary to maintain a certain reagent ratio. For example, it has been found $[78,84]$ that, if the concentration of trivalent metal (e.g., iron) ions in solution exceeds that of phosphate ions, precipitation with urea yields under these conditions gels 
from which powders of tertiary iron phosphate, rather than MPA, are obtained.

According to the procedures considered above, MAPs are synthesized from dilute $(0.01-1.00 \mathrm{M})$ solutions of trivalent metal salts or from phosphoric acid solutions containing compounds of trivalent metals as admixtures (in an amount not exceeding 3\%). Unfortunately, use of dilute solutions for synthesis of MAPs suitable for FPAs is unproductive. It is more economical to obtain MAPs for fire-protection and fire-extinguishing purposes as concentrated fine dispersions.

Data on MAPs in products obtained under industrial conditions from concentrated solutions are very scarce. A method for synthesis of a powdery insoluble fireretardant agent from nepheline used in manufacture of fiberboards has been described [29, 31]. A mixture of aluminum phosphates, with the amount of aluminumammonium phosphates not exceeding $3 \%$, is produced by reacting an aluminosilicate mineral, nepheline, with phosphoric acid, with a subsequent ammoniation with gaseous ammonia and a thermal treatment of the product at $200^{\circ} \mathrm{C}$. As a result, a mixture of compounds is formed, whose composition was not determined by the authors. This fire-retardant agent is introduced in the stage of fiberboard fabrication in the solid state, with the degree of its dispersity considered unimportant. To obtain a highly dispersed substance, the fire-retardant agent should be additionally thoroughly ground and sieved, with the required fractions collected. However, this procedure fails to provide the degree of dispersity required for obtaining fire-extinguishing dispersions. The nepheline fireretardant agent seems to be the only example of synthesis and application of metal-ammonium phosphates as flame retardants. However, it has been shown that this product has a number of disadvantages, such as low dispersity and poor water and atmosphere resistance, which adversely affects its fire-protecting efficiency.

Consequently, the prescribed chemical stability of MAPs, determined by their composition, should be provided by chosen synthesis conditions. According to published data, the most promising for application as FPA components are aluminum-ammonium or ironammonium phosphates produced as amorphous gel-like bulky precipitates from concentrated metal phosphate aqueous solutions by precipitation with an ammonia solution and(or) alkali metal hydroxides at $\mathrm{pH}$ close to 5.5. The problems of obtaining stable aqueous dispersions on the basis of these insoluble compounds are not considered in literature sources.

\section{SYNTHESIS CONDITIONS, CHEMICAL AND PHASE COMPOSITION, AND PROPERTIES OF METAL-AMMONIUM PHOSPHATES IN THE CASE OF JOINT PRESENCE IN SOLUTION OF IONS OF METALS OF VARIOUS VALENCES}

Rather frequently, of practical interest for obtaining effective FPAs with prescribed properties are complex systems including several water-soluble or -insoluble fire-retardant additives of varied nature. Each component in an FPA executes it fire-extinguishing function in the gaseous or condensed phase.

Published data on the synthesis conditions of double phosphates of metals and ammonium (or an alkali metal) from solutions in the joint presence of several ions of divalent or di- and trivalent metals are scarce. However, consideration of the few available literature sources makes it possible to invoke some principles of MAP synthesis for a purposeful development of new FPAs with prescribed properties and improvement of the efficiency of those already available.

According to published data [87], MAPs are formed in the case of a joint pairwise presence $n$ solution of ions of divalent metals ( $\mathrm{Mg}, \mathrm{M}, \mathrm{Co}, \mathrm{Zn}$ ) having close radii only upon addition to a mixture of salt solutions of these metals a four-to-ninefold excess of ammonium hydrophosphate. By contrast, it has been shown [88] that, if metal ions are present in solution in an excess relative to ammonium ions and phosphate ions, there occur processes of mutual substitution of metal ions, which yield, instead of MAPs, double phosphates of the type $\mathrm{Me}_{x} \mathrm{M}_{x-y} \mathrm{PO}_{4}(\mathrm{Me}=\mathrm{Mg}, \mathrm{M}=\mathrm{Mn}, \mathrm{Co}, \mathrm{Zn})$ as a number of solid solutions. When the cation sizes are markedly different (if, e.g., magnesium ions are replaced with calcium ions), a mechanical mixture of tertiary metal phosphates is formed. At the equimolar ratio between calcium nitrate and ammonium hydrophosphate in the system $\mathrm{Ca}\left(\mathrm{NO}_{3}\right)_{2}-\mathrm{Mg}\left(\mathrm{NO}_{3}\right)_{2}-\left(\mathrm{NH}_{4}\right)_{2} \mathrm{HPO}_{4}-\mathrm{NH}_{4} \mathrm{OH}-$ $\mathrm{H}_{2} \mathrm{O}$ at $\mathrm{pH} 8$, MAP was not precipitated either, but basic magnesium-containing calcium phosphate of composition $\mathrm{Ca}_{10-x}\left(\mathrm{MgHPO}_{4}\right)_{x}\left(\mathrm{PO}_{4}\right)_{6-x}(\mathrm{OH})_{2-x}$ was formed [22]. In this case, the content of magnesium ions was $1-6 \%$ relative to that of calcium ions.

Mixed MAPs are obtained when an ammonia solution is used to neutralize a metal phosphate solution in which aluminum and iron(III) ions are simultaneously present in a molar ratio $\mathrm{Fe}: \mathrm{Al}=(0.1-3): 1.0[24,70]$. In this case, 
a number of phosphate solid solutions in which metals substitute each other are obtained.

There is hardly any published evidence about MAP synthesis conditions from solutions containing simultaneously ions of di- and trivalent metals, phosphate ions, and ions of ammonium (or an alkali metal). For example, only a single report [89] described how various compounds are formed at various $\mathrm{pH}$ values, orders of pouring together, and reagent ratios in the system $\mathrm{CaCl}_{2}-\mathrm{AlCl}_{3}-\left(\mathrm{NH}_{4}\right)_{2} \mathrm{HPO}_{4}-\mathrm{NH}_{4} \mathrm{OH}$ in order to obtain calcium-containing materials for bioceramics. Precipitates of complex composition of the type $\mathrm{Ca}_{10}\left(\mathrm{PO}_{4}\right)_{6}(\mathrm{OH})_{2}(0.6-2)\left[\left(\mathrm{NH}_{4}\right)_{x} \mathrm{Al}(\mathrm{OH})_{3+x}\right] \cdot y \mathrm{H}_{2} \mathrm{O}$ were only obtained from strongly alkaline solutions ( $\mathrm{pH}$ 9.6) in the presence of an excess amount of calcium chloride and addition of the aluminum salt at the end of synthesis. At lower $\mathrm{pH}$ values (8.1-8.2), the composition of the precipitate changed: it contained a mixture of $\mathrm{Ca}_{3} \mathrm{PO}_{4}$ and $\mathrm{Al}(\mathrm{OH})_{3} \cdot y \mathrm{H}_{2} \mathrm{O}$. The synthesis conditions in a neutral medium have not been studied.

As a rule, other reports describe the conditions in which complex phosphates are obtained in autoclaves in hydrothermal synthesis conditions, with a prolonged temperature treatment under pressure in the joint presence, in addition to phosphate ions, of cations of metals with various valences $\left(\mathrm{M}^{\mathrm{L}}-\mathrm{M}^{\mathrm{IV}}\right)$, where $\mathrm{M}^{\mathrm{I}}=\mathrm{Li}-$ Cs, $\mathrm{Ag}$, or $\mathrm{NH}_{4}^{+}$ion; $\mathrm{M}^{\mathrm{II}}=\mathrm{Ca}, \mathrm{Sr}, \mathrm{Ba}$; and(or) $\mathrm{M}^{\mathrm{III}}=\mathrm{Al}$, $\mathrm{Ga}, \mathrm{Fe}, \mathrm{Sc}, \mathrm{In} ; \mathrm{M}^{\mathrm{I}}=\mathrm{K}, \mathrm{M}^{\mathrm{III}}-\mathrm{Al}, \mathrm{Fe}, \mathrm{Cr}, \mathrm{Sc}$, In; and(or) $\mathrm{M}^{\mathrm{IV}}=\mathrm{Ti}[90]$.

It should be noted that a characteristic feature of anhydrous double phosphates that are based on divalent metals of different nature [of the type $\mathrm{M}_{2}{ }^{\mathrm{II}} \mathrm{Me}{ }^{\mathrm{II}}\left(\mathrm{PO}_{4}\right)_{2}$ ] or di- and trivalent metals and contain no ammonium ions, hydroxide ions, or acid phosphate groups is that they do not decompose under heating and undergo only isomorphic transformations up to their melting points $\left(\sim 1000^{\circ} \mathrm{C}\right)[61]$. Consequently, the service efficiency of these compounds as fire-retardant agents for FPAs will depend on the quality of the insulating coating on the surface of a burning material, which should be taken into account when choosing the synthesis conditions of fire-extinguishing systems.

\section{CONCLUSIONS}

Analysis of the published evidence about syntheses of double phosphates of di- and trivalent metals and ammonium from solutions enables the following conclusions.
(1) Synthesis of individual double phosphates of diand(or) trivalent metals and ammonium from solutions is the simplest and most economical way to obtain products for fire protection and fire extinguishing in the case of natural and synthetic polymeric materials. The synthesis conditions include mixing of salt solutions or interaction of metal-containing raw materials with phosphoric acid at elevated temperatures $\left(20\right.$ to $\left.100^{\circ} \mathrm{C}\right)$ and neutralization of metal phosphates solutions with alkaline solutions. The chemical and phase composition of the products depends on the nature of the substances used, their concentration, quantitative ratios, order and rate of reagent mixing, duration of keeping under mother liquor, and conditions of the subsequent thermal treatment. The aggregative state of the products (dispersions, pastes, powders) is also determined by their synthesis conditions.

(2) The products obtained may contain crystalline and amorphous hydroxo and hydrophosphates of polyvalent metals, double metal-ammonium phosphates, and phosphates of alkali metals and ammonium. Metal-ammonium phosphates are of interest for use as components of fire-protective and fire-extinguishing agents because of the following: they contain nitrogen and phosphorus exhibiting a synergistic effect; products can be obtained in various aggregative states with various dispersities, which enables their use to impart fame resistance to both synthetic and natural combustible materials; the phosphates possess a wide range of properties (formation of melts, foamed structures, and volatile thermolysis products) needed when choosing fire retardants for polymers of various classes.

(3) So far there has hardly been any evidence about methods and conditions of synthesis of metal-ammonium phosphates of formulations on their basis, used in fire extinguishing. Nevertheless the general approaches to synthesis of metal-ammonium phosphates, presented in the reviewed communications are undoubtedly useful, but insufficient for a purposeful synthesis of products with required properties.

(4) As the most promising compounds to be used as a fire-retardant component of fire-protective and fireextinguishing agents for natural combustible materials (wood, peat) can serve phosphates of di- and(or) trivalent metals and ammonium based on such metals as, e.g., magnesium, aluminum, and(or) iron. This is due to the ability of these phosphates to form stable aqueous dispersions of amorphous poorly soluble 
metal-ammonium phosphates, ecological safety, and comparatively low cost.

\section{REFERENCES}

1. Aseeva, R.M. and Zaikov, G.E., Gorenie polimernykh materialov (Combustion of Polymeric Materials), Moscow: Nauka, 1981.

2. Agueda, A., Pastor, E., and Planas, E., Progr. Energy Combustion Sci., 2008, vol. 34, pp. 782-796.

3. Stevens, R., Es, D.S.V., Bezemer, R., and Kranenbarg, A., Polym. Degrad. Stab., 2006, vol. 91, pp. 832-841.

4. Jiang, J., Lim J., Hu, J., and Fan, D., Constr. Building Mater., 2010, vol. 24, no. 12, pp. 2633-2637.

5. Bogdanova, V.V. and Kobets, O.I., Polimernye materialy ponizhennoi goryuchesti: Sbornik materialov VI Mezhdunarodnoi konferentsii (Proc. VI Int. Conf. on Poymeric Materias with Lowerred Combustibility), Vologda: Vologda Gos. Tekh. Univ., 2011, pp. 34-36.

6. Zhurova, V.G., Analiticheskaya khimiya i fiziko-khimicheskie metody analiza (Analytical Chemistry and Physicochemcal Methods of Analysis), Smolensk: Universum, 2008.

7. Alekseev, V.G., Pospelov, I.P., and Kornilov, M.V., J Anal. Chem., 2000, vol. 55, no. 11, pp. 1055-1057.

8. Radovenchik, V.M., Glushko, O.V., and Kolomitsev, D.V., Ekotekhnol. Resursosberezhenie, 2004, no. 5, pp. 55-58.

9. Yetilmezsoy, K. and Sapci-Zengin, Z., J. Hazard. Mater., 2009, vol. 166, pp. 260-269.

10. US Patent 5294348 (publ. 1994).

11. Timofeeva, A.S., Krakht, L.N., and Chichvarin, A.V., Nauch.-Teor. Zh. Fundamental'nye issledovaniya, Ros. Akad. Estestvoznaniya (http://www.rae.ru), 2009, no. 5, pp. 1-2.

12. Chimenos, J.M., Fernandes, A.I., Villalba, G., et al., Water Res., 2003, vol. 37, pp. 1601-1607.

13. Shul'ga, N.V. and Samuskevich, V.V., Russ. J. Appl. Chem., 2002, vol. 75 , no. 3, pp. 378-384.

14. Zabukovec-Logar, N., Mrak, M., Kaučič, V., and Golobič, A., J. Solid State Chem., 2001, vol. 156, no. 2, pp. $480-486$.

15. Stalder, S.M. and Wilkinson, A.P., J. Mater. Chem., 1998, vol. 8, no. 1, pp. 261-263.

16. Borton, A.I., Bortun, L.N., and Clearfield, A., Solv. Extr. Ion Exch., 1998, vol. 16, no. 2, pp. 669-681.

17. US Patent 8569557 (publ. 2013).

18. Sadykov, V.A., Pavlova, S.N., Chaikina, M.V., et al. Khim. Interesakh Ustoichiv. Razvitiya, 2002, no. 10, pp. 227-235.

19. Ovorweg, A.R., De Haan, J.W., Magusin, P.C.M.M., et al.,
Chem. Mater., 1999, vol. 11, no. 7, pp. 1680-1686.

20. Orlova, O.V. and Fomicheva, T.N., Tekhnologiya lakov $i$ krasok (Technology of Paints and Varnishes), Moscow: Khimiya, 1990.

21. Safronova, T.V. and Putlyaev, V.I., Nanosist.: Fiz., Khim., Matemat., 2013, no. 4 (1), pp. 24-47.

22. Barinov, S.M., Uspekhi Khim., 2010, no. 1 (79), pp. 21-32.

23. Abyzov, V.A., Klinov, O.A., and Ryakhovskii, E.N., Vestn. Yuzh.-Ural. Gos. Univ., issue 4, Ser. Stroit. Arkhitekt., 2007, no. 14 (86), pp. 12-14.

24. Tekhnologiya fosfatnykh i kompleksnykh udobrenii (Technology of Phosphate and Integrated Fertilizers), Evenchik, S.D. and Brodskii, A.A., Eds., Moscow: Khimiya, 1987.

25. US Patent 6120574 (publ. 2000).

26. Doyle, J.D. and Parsons, S.A., Water Res., 2002, vol. 36, pp. 3925-3940.

27. Nelson, N.O., Mikkelsen, R.L., and Hesterberg, D.L., Bioresource Technol., 2003, vol. 89, pp. 229-236.

28. Lapina, L.M., Usp. Khim., 1968, vol. 37, no. 9, pp. 16261641.

29. Lapina, L.M., Usacheva, N.I., and Kizas, A.Yu., Issledovaniya po khimii i tekhnologii udobrenii, pestitsidov, solei: Sbornik statei (Studies in Chemistry and Technology of Fertilizers, Pesticides, and Salts: Coll. of Papers), Moscow: Akad. Nauk SSSR, 1966, pp. 225-230.

30. Lapina, L.M., Grishina, I.A., Usacheva, N.I., and Mironovich, I.M., Problemy khimii i khimicheskoi tekhnologii. Nekotorye novye napravleniya khimicheskoi tekhnologii i khimizatsii sel'skogo khozyaistva (Problems of Chemistry and Chemical Technology: Some New Areas of Chemical Technology and Chemicalization of Agriculture), Moscow: Nauka, 1977, pp. 252-260.

31. Mironovich, I.M., Vol'fkovich, S.I., Lapina, L.M., and Sorin, V.S., Khim. Prom-st', 1975, no. 3, pp. 47-49.

32. Grishina, N.A., Lapina, L.M., Podlesskaya, A.V., and Tavrovskaya, A.Ya., Izv. Akad. Nauk SSSR, Neorg. Mater., 1973, vol. 9, no. 11, pp. 2027-2032.

33. Konstant,Z.A. and Dindune,A.P. in Fosfaty dvukhvalentnykh metallov (Phosphates of Divalent Metals), Riga: Zinatne, 1987.

34. Wallez, G., Colbeau-Justin, C., and Le Mercier, T., J. Solid State Chem., 1998, vol. 136, no. 2, pp. 175-180.

35. Yacubovich, O.V., Karimova, O.V., Dimitrova, V., and Massa, W., Acta Crystallogr. C, 1999, vol. 55, no. 2, pp. 151-153.

36. Harrison, W.T., Sobolev, A.N., and Phillips, M.L., Acta Crystallogr. C, 2001, vol. 57, no. 5, pp. 508-509. 
37. Carling, S.G., Day, P., and Vissen, D., Inorg. Chem., 1995, vol. 34, no. 15, pp. 3917-3927.

38. Le, S.N. and Navrotsky, A., J. Solid State. Chem., 2008, vol. 181, pp. 20-29.

39. Lu, Z., Chen, H., Robert, R., et al., Chem. Mater., 2011, vol. 23, pp. 2848-2859.

40. Nawa, K., Michioka, C., Yoshimura, K., et al., J. Phys.: Conference Ser., 2012, vol. 344, pp. 12-24. http:// iopscience.iop.org/1742-6596/344/1/012024

41. Pujana, A., Pizarro, J.L., Lezama, L., et al., J. Mater. Chem., 1998, vol. 8, no. 4, pp. 1055-1060.

42. Touaiher, M., Bettach, M., Benkhouja, K., et al., Annales de Chimie - Science des Matüriaux, 2001, vol. 26, no. 3, pp. 49-54.

43. Galkova, T.N., Pasevska, B., Samuskevich, V.V., et al., J. Therm. Calorim., 2000, vol. 60, no. 3, pp. 1019-1032.

44. Shkorik, N.A., Samuskevich, V.V., and Prodan, E.A., Neorg. Mater., 1993, vol. 29, no. 5, pp. 667-671.

45. Samuskevich, V.V. and Prodan, E.A., Vestsi Akad. Navuk Belarusi, Ser. Khim. Navuk, 1992, nos. 3-4, pp. 26-30.

46. Samuskevich, V.V. and Prodan, E.A., Zh. Neorg. Khim., 1993, vol. 38, no. 5, pp. 804-808.

47. Kopilevich. V.A., Shchegrov, L.N., and Panchuk, T.K., Zh. Neorg. Khim., 1992, vol. 37, no. 4, pp. 754-761.

48. Bishko, Ya.V., Vyazovov, V.V., and Grabovenko, V.A., Khim. Prom-st', 1982, no. 3, pp. 190-191.

49. Turaev, Z., Khakimova, V.K., and Tukhtaev, S.N., Uzb. Khim. Zh., 1985, no. 4, pp. 43-45.

50. Vyazovov, V.V., Grabovenko, V.A., and Bishko, Ya.V., Zh. Neorg. Khim., 1980, vol. 25, no. 8, pp. 2164-2167.

51. Mukhamedzhanov, M., Khakimova, V.K., Vishnyakova, A.A., and Sultanov, S., Udobreniya, v $2 \mathrm{kh}$ tomakh (Fertilizers, in 2 vols.), Tashkent: FAN, 1973, vol. 1, pp. 119-124.

52. RF Patent 2051089 (publ. 1995).

53. US Patent 6451361 (publ. 2002).

54. US Patent 6476082 (publ. 2002).

55. US Patent 5374294 (publ. 1994).

56. Prodan, E.A. and Samuskevich, V.V., Stabil'nost' $i$ reaktsionnaya sposobnost'fosfornykh solei (Stability and Reactivity of Phosphorus Salts), Minsk: Navuka i Tekhnika, 1994.

57. Feltz, A., Amorphe und Glasartige Anorganishe Festkorper, Berlin: Akademie-Verlag, 1983

58. Korol'chenko, A.Ya. and Petrova, E.A., Ros. Khim. Zh. (Zh. Ros. Khim. O-va im. D.I. Mendeleeva), 2003, vol. 47, no. 4, pp. 49-54.
59. Lovi, A. and Lovi, C., Rev. Chim., 1993, vol. 44, no. 7, pp. 648-652.

60. Grishin, A.M., Matematicheskie modelirovanie lesnykh pozharov $i$ novye sposoby bor'by s nimi (Mathematical Simulation of Forest Fires and New Methods for Their Control), Novosibirsk: Nauka, 1992.

61. Lepilina, R.G. and Smirnova, N.M., Termogrammy neorganicheskikh fosfatnykh soedinenii: Spravochnik (Thermograms of Inorganic Phosphate Compounds: Reference Book), Leningrad: Nauka, 1984.

62. Sychev, I.M., Neorganicheskie klei (Inorganic Glues), Leningrad, 1989.

63. Filaretov, A.A., Zhizhin, M.G., and Komissarova, L.N., J. Solid State Chem., 2002, vol. 66, no. 32, pp. 362-368.

64. Bircsakm Z. and Harrison, W.T., Acta Crystallogr. C, 1998, vol. 54, no. 9, pp. 1195-1197.

65. Ruchkina, O.V., Belokoneva, E.L., and Dimitrova, O.V., Russ. J. Inorg. Chem., 2003, vol. 48, no. 5, pp. 632-635.

66. Stus', N.V., Slobodyanik, M.S., and Nagornii, P.G., Ukr. Khim. Zh., 2000, vol. 66, nos. 1-2, pp. 72-75.

67. Whittingham, M.S., Song, Y., Lutta, S., et al., J. Mater. Chem., 2005, vol. 15, pp. 3362-3379.

68. Komissarova, L.N., Zhizhin, M.G., and Filaretov, A.A., Usp. Khim., 2002, vol. 71, no. 8, pp. 707-740.

69. Tananaev, I.V., Zh. Neorg. Khim., 1980, vol. 25, no. 1, pp. 45-56.

70. Tananaev, I.V. and Orlovskii, V.P., Zh. Neorg. Khim., 1986, vol. 31, no. 8, pp. 1923-1930.

71. Laimi, B., Hidouri, M., and Amara, M.B., Acta Crystallogr. C, 2002, vol. 58, no. 11, pp. 1156-1158.

72. Belkhiria, M.S., Laaribi, S., and Amara, B.H., Ann. Chim. Sci. Mater., 1998, vol. 23, nos. 1-2, pp. 117-120.

73. Belokoneva, E.L., Ruchkina, E.A., and Dimitrova, O.V., Russ. J. Inorg. Chem., 2003, vol. 48, no. 3, pp. 380-384.

74. Trobajo, C., Espina, A., Jaimez, E., et al., J. Chem. Soc., Dalton Trans., 2000, no. 5, pp. 787-790.

75. Gobechiya, E.R., Kabalov, Yu.K., and Pet'kov, V.I., Kristallograf., 2004, vol. 49, no. 5, pp. 829-834.

76. Orlova, A.I. and Koryttseva, A.K., Kristallograf, 2004, vol. 49, no. 5, pp. 811-820.

77. Greben'ko, N.V., Eshchenko, L.S., and Kushel', M.I., Izv. Vyssh. Uchebn. Zaved., Khim. Khim. Tekhnol., 1976, vol. 19, no. 7, pp. 1070-1071.

78. Greben'ko, N.V., Eshchenko, L.S., and Pechkovskii, V.V., Zh. Neorg. Khim., 1976, vol. 26, no. 10, pp. 2660-2664.

79. Lapina, L.M., Grishina, I.A., Usacheva, N.I., and Portnova, N.L., Zh. Prikl. Khim., 1972, vol. 45, no. 1, pp. 6-11.

80. Lapina, L.M. and Grishina, I.A., Trudy NIUIF, 1972, 
issue 221, pp. 56-62.

81. Golub, A.M. and Boldog, I.I., Zh. Neorg. Khim., 1974, vol. 19, no. 4, pp. 918-921.

82. Golub, A.M. and Boldog, I.I., Zh. Neorg. Khim., 1974, vol. 19, no. 7, pp. 1756-1760.

83. Prodan, I.E., Eshchenko, L.S., and Pechkovskii, V.V., Zh. Neorg. Khim., 1983, vol. 28, no. 3, pp. 560-565.

84. Eshchenko, L.S., Pechkovskii, V.V., Prodan, I.E., et al., Zh. Neorg. Khim., 1982, vol. 27, no. 3, pp. 802-805.

85. Golub, A.M. and Boldog, I.I., Izv. Vyssh. Uchebn. Zaved., Khim. Khim. Tekhnol., 1975, vol. 18, no. 1, pp. 21-25.
86. Yakubovich, O.V. and Dadashov, M.S., Kristallografiya, 1988, vol. 33, no. 4, pp. 848-853.

87. Antraptseva, N.M. and Shchegrov, L.N., Zh. Neorg. Khim., 1983, vol. 28, no. 10, pp. 2523-2528.

88. Antraptseva, N.M. and Shchegrov, L.N., Zh. Neorg. Khim., 1994, vol. 39, no. 5, pp. 750-753.

89. Ezhova, Zh.A., Orlovskii, V.P., and Koval', E.M., Russ. J. Inorg. Chem., 1999, vol. 44, no. 1, pp. 102-105.

90. Zatovskii, I.V., Slobodyanik, N.S., Ostapenko, G.T., et al., Elektron. Nauch.-Inform. Zh., Vestn. Otd. Nauk Zemle Ros. Akad. Nauk, 2003, no. 1 (21). http://www.scgis.ru/russian/ cp1251/h_dgggms/1-2003/informbul-1/hydroterm-2.pdf. 